\title{
PREVALENCE OF PULMONARY TUBERCULOSIS IN FAR WESTERN NEPAL
}

\author{
Joshi Y P*, Mishra P N", Joshi D D* \\ * National Zoonosis and Food Hygiene Research Centre, Chagal, Kathmandu, Nepal \\ ** Central Department of Zoology, Tribhuvan University, Kirtipur, Nepal
}

\begin{abstract}
Keeping in view of high prevalence of tuberculosis in far western development region in different reports, a door to door survey of $\mathbf{1 2 5}$ household was carried out randomly in Mahendra Nagar municipality ward no 13 of Kanchanpur district to pick up symptomatics suggestive of pulmonary tuberculosis and find the prevalence in the target population. A total of 200 sputum specimens from 70 symptomatics within the age range of 10-80 years were collected and subjected to smear microscopy by Ziehl - Neelsen's method. Out of 10 positive cases $(14.28 \%)$, infection in males and females was $80 \%$ and $20 \%$ respectively. The infection was found in the productive age group 20-69. The highest prevalence was obtained in 20-29 age group (25\%) followed by 40-49 (11\%), 30-39 $(9 \%), 50-59(8 \%)$ and 60-69 (8\%). The diagnostic yield of single sputum specimen examined was insufficient in field condition, especially where the sputum positivity was low. Of the three sputum smears examined, the early morning specimen had the best result.
\end{abstract}

Key Words: Pulmonary tuberculosis, prevalence, sputum smears.

\section{INTRODUCTION}

Tuberculosis (TB) is a disease of great antiquity and protean clinical manifestations; has almost certainly caused more suffering and death than any other bacterial infection. ${ }^{1}$ It is among the top ten causes of global mortality in humans. ${ }^{2}$

TB is an immense problem in Nepal causing great suffering and death. About $60 \%$ of adults and $45 \%$ of general population have been infected with the disease. Nearly 90,000 people currently have TB, half of these are infectious and annual death is about 8,000-11,000. The majority of these patients are of economically active age groups of $15-45$ years..$^{3-5}$

Generally, the prevalence of infection is higher in men than women and adolescence, because they have increased number of social contacts in contrast to women who tend to stay at home or work in the fields. There is particularly high incidence of TB among the residents of common lodging houses. ${ }^{6}$ This study was undertaken to asses the age and sex prevalence of smear positive tuberculosis in the ward no. 13 of Mahendra Nagar municipality of Kanchanpur district.

\footnotetext{
Address for correspondence :

Yadav Prasad Joshi

National Zoonosis and Food Hygiene Research Centre, Chagal

GPO Box: 1885, Kathmandu, Nepal

Email: yadav_joshi@yahoo.co.in
}

Received Date : $24^{\text {th }}$ Jan, 2005

Accepted Date : 30 $0^{\text {th }}$ May, 2005 


\section{MATERIALS AND METHODS}

A cross-sectional study was conducted from March 2002 to August 2002. Out of 3,162 households, 125 were selected randomly by using random number table. A structured questionnaire was prepared focusing on signs and symptoms of TB and tested in a separate village, which was not included in the study. The final set of questionnaire was discussed primarily with the household head of each selected house.

The questionnaires were analyzed for identifying the pulmonary TB suspects. The selection was done if one or more of the following symptoms were present: persisting cough for two weeks or more; chest pain; fever and haemoptysis. Seventy individuals (40 males and 30 females) from 66 household were selected as tuberculosis suspects and instructed for collection of sputum samples in sterilized vials. They were required to give three sputum smears (first spot, second early morning, third spot specimen) over two consecutive days. Patients with positive smears in second and third grading scales were not requested for additional sample. All the positive slides from the patients were carried to National Tuberculosis Centre (NTC), Thimi, Bhaktapur for verification and grading.

Smear microscopy was done in the laboratory of District Public Health Office (DPHO), Kanchanpur under aseptic conditions by Ziehl-Neelsen's (Z-N) staining process and examined under 300 visual field (VF) of compound light microscope before reporting as negative.

The numbers of bacilli seen in a stained smear reflect disease severity and patients' infectivity. ${ }^{7}$ The number of bacilli was recorded according to the recommendation of American Lung Association (ALA). ${ }^{1}$ The collected data were analyzed for statistical purposes by using EP16 program.

\section{RESULTS}

The population of the ward was $50.8 \%$ males and $49.2 \%$ females $(n=19,734)$ living in a total of 3,162 households. The study comprised $72.8 \%$ males and $27.2 \%$ females $(n=125)$ on the same number of households. The total population of sur-

Table I : Age and sex wise distribution of tuberculosis suspects

\begin{tabular}{lcccc}
\hline \multirow{2}{*}{$\begin{array}{c}\text { Age group } \\
\text { (in years) }\end{array}$} & \multicolumn{2}{c}{ Male } & \multicolumn{2}{c}{ Female } \\
\cline { 2 - 5 } & No & $\%$ & No & \% \\
\hline $10-20$ & 2 & 5 & 0 & 0 \\
$20-30$ & 4 & 10 & 1 & 3 \\
$30-40$ & 6 & 15 & 2 & 6.5 \\
$40-50$ & 11 & 27.5 & 14 & 47 \\
$50-60$ & 9 & 22.5 & 8 & 27 \\
$60-70$ & 5 & 12.5 & 3 & 10 \\
70 and above & 3 & 7.5 & 2 & 6.5 \\
\hline
\end{tabular}

veyed household was 543 . Of them, $53.04 \%$ were males and $46.96 \%$ were females. Table I shows the ratio of male to female with tuberculosis symptoms in relation to their age. Of the 70 suspects, $57.14 \%$ were males and $42.86 \%$ were females.

The collected AFB positive sputum samples from males and females were $56 \%$ and $44 \%(\mathrm{n}=200)$; and $78.95 \%$ and $21.05 \%$ $(n=19)$, respectively. Age wise prevalence was observed with respect to total examined smear and percentage of smears showing smear positive. Prevalence rate of the disease was $9 \%$ in average i.e. $13 \%$ in males and $5 \%$ in females. Highest prevalence rate of the disease in males and females were in between the age groups of 20-30 and 50-60 respectively. (Figure 1)

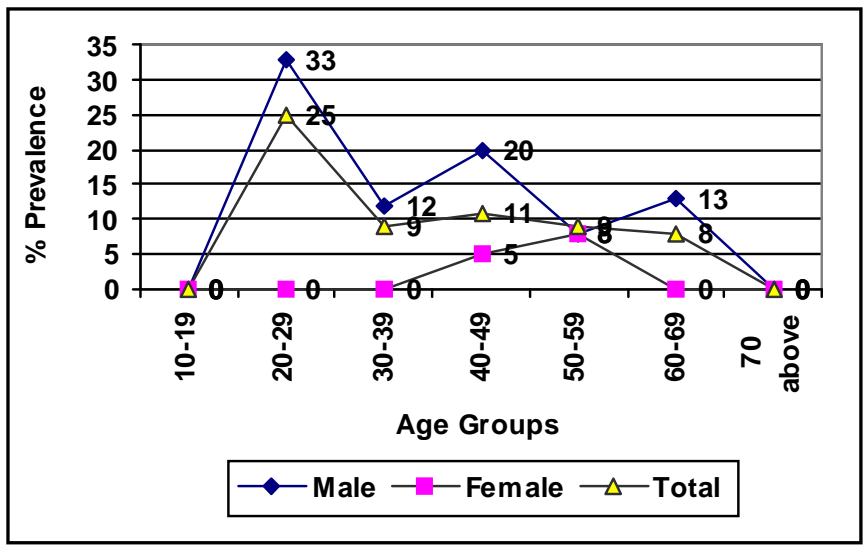

Fig.1: Age and sex prevalence of tuberculosis by sputum smear microscopy

Collected sputum samples were examined with Z-N stain followed by smear microscopy. Of the 200 sputum samples, 19 slides were positive from 10 diagnosed PTB patients.

Table II shows age wise verification of 10 positive cases with combinations of positivity in three grading scales. The overall sputum positively was $9.50 \%$. Highest numbers of sputum positive cases were detected from morning specimen i.e. $70 \%$.

Among 40 male subjects $20 \%$ were positive whereas among 30 female subjects $6.67 \%$ were positive. Prevalence of tuberculosis carriers was $14.28 \%$ of target population.

\section{DISCUSSION}

In humans, patients with sputum positive on direct smear examination are the principal source of infection and this technique is the most reliable diagnostic tool for the pulmonary sputum positive cases of TB. Of the three-sputum specimens, the early morning had the best result as compared to other two spot specimens. Thus, two sputum specimens, one of which is overnight, may be sufficient and dependable under field condition where it is preferable to avail every opportunity to examine sputum. ${ }^{8,9}$ In other study the overall sputum positivity con- 
Table II : Age-wise AFB smears positivity and grading

\begin{tabular}{lccccc}
\hline $\begin{array}{c}\text { Age groups } \\
\text { (in years) }\end{array}$ & $\begin{array}{c}\text { Total no. of } \\
\text { examined slides }\end{array}$ & $\begin{array}{c}\text { Total no. of } \\
\text { positive slides }\end{array}$ & $\begin{array}{c}\text { Total no of } \\
\text { positive cases }\end{array}$ & \multicolumn{2}{c}{ Grading } \\
\hline $10-20$ & 6 & 0 & 0 & $\mathbf{1}^{+}$ & $\mathbf{2}^{+}$ \\
$20-30$ & 12 & 3 & $1 * * *$ & - & - \\
$30-40$ & 23 & 2 & $4 * *$ & $1^{+}$ & - \\
$40-50$ & 71 & 8 & $2 * * *$ & $1^{+}, 1^{+}, 1^{+}, 1^{+}$ & $2^{+}$ \\
$50-60$ & 49 & 4 & $1^{+}$ & - \\
$60-70$ & 24 & 2 & 0 & - & - \\
$70 \&$ above & 15 & 0 & - & $1^{+}$ & - \\
\hline
\end{tabular}

* Positive by first specimen (Spot).

** Positive by second specimen (Morning).

*** Positive by third specimen (Spot).

tent was around $25 \%$, and $90.5 \%$ sputum positive patients were detected by first spot specimen and early morning specimen, ${ }^{7}$ which is similar with our findings.

The prevalence of an untreated infectious case of TB in crowded, poorly ventilated building confer a considerable risk for the infection to other clients and shelter personals. ${ }^{10,11}$ The higher prevalence of disease in males was reported from the tuberculin survey and histopathological examination of TB cases. ${ }^{12,13}$

In our study, the prevalence rate of the disease in examined smears was $9 \%$ on average. Sex wise prevalence was more in males (13\%) than females (5\%). Among 40 male subjects $20 \%$ were positive whereas among 30 female subjects $6.67 \%$ were positive. The males move frequently and are more likely to be exposed to infection. Hence, the prevalence of infection is higher in men than women and adolescence. ${ }^{6}$ The biological differences, such as increased susceptibility in males might be important. Women may progress more rapidly to the disease and die more rapidly, as they have less access to health care services. About $75 \%$ of those infected with tuberculosis are under the age of $50 .{ }^{14}$ The majority of these patients are people of economically active age groups of 15-45 years which are most productive years of life. ${ }^{15}$ Among the 10 positive cases $70 \%$ were from the productive age group, but none of the TB patients were from age groups below 19, and 70 and above.

\section{CONCLUSION}

It can be concluded that, three sputum smears (early morning) are effective for screening of pulmonary tuberculosis symptomatics. Reduction in the number of positive smears cases is expected to reduce the prevalence rate. However, more studies in different situations and ethnic variation of the disease are needed.

\section{ACKNOWLEDGMENT}

The authors gratefully acknowledge to the laboratory staff of DPHO, Kanchanpur and B. P. Chaudhary, NTC for their expert laboratory support in smear microscopy and verification. We thank to Dr. D. S. Bam, Director NTC for his valuable guidelines and in providing hospital facilities. We would also extend our deep memory to the residents of study area for their significant contribution in the study.

This research work was financially supported by NZFHRC and DDJ Research Foundation, Chagal, Kathmandu, Nepal for which we are grateful.

\section{REFERENCES}

1. Parija SC, Kumar N, Singh NP. Sputum Microscopy. A Practical Manual. Venus, New Delhi. 1998: 1-3.

2. Borgdorff MW, Katherine F, Jaap FB. Interventions to reduce tuberculosis mortality and transmission in low and middle income countries. Bulletin of WHO 2002; 80, 3: 217-227.

3. National Tuberculosis Programme. Tuberculosis Control in Nepal. Status report: 1998-2003, Thimi, Nepal: National Tuberculosis Centre, 2003.

4. Bam DS. TB control programme in Nepal. Souvenir, The Nepal Association of TB and Chest Physicians 2002:2.

5. National Tuberculosis Programme. Tuberculosis Control in Nepal. Annual report. Thimi, Nepal: National Tuberculosis Center, 1999.

6. Collis C, Kelly P, Byrne C, Denhan F, Clancy L. Is bovine atypical or resistant tuberculosis a problem?. Irish Med J 1987:80:66-7.

7. Sarin R, Mukerjee S, Singla N. Sharma PP. Diagnosis of tuberculosis under RNTCP: Examination of two or three sputum specimens. Ind $\mathrm{J}$ Tub 2001; 48:13-16.

8. Toply \& Wilson. Principles of Bacteriology, Virology and Immunity. Parkers MT, Duerden BI, Butler \& Taner Ltd. London $8^{\text {th }}$ ed 1990; 2. 
9. Moda G, Daborn CJ, Grange J M, Cosivi O. The zoonotic importance of Mycobacterium bovis. Tubercle and Lung Disease 1996; 77 (2): 1035.

10. Nolan CM, Elarth AM, Barr H, Mahdi SA, Risser DR. An outbreak of tuberculosis in a shelter for homeless men. Am Rev Respr Dis 1991;143:257-61.

11. Krishna Murthy MS, Channabasaviah R, Nagaraj AV, Chandrasekhar $P$. Incidence of tuberculosis infection in a South Indian village with a single sputum positive case: An epidemiological case study. Ind J Tub 1991; 38: 123-30.
12. Smith I. Tuberculin survey in Gorkha district: Proceeding of the seminar and workshop on National Tuberculosis Control Program (NTCP), Kathmandu. Japan International Cooperation Agency (JICA), 1993; 936.

13. Shrestha HG. Extra-pulmonary tuberculosis in Nepal. JNMA 1989; 916.

14. Hornick DB. Tuberculosis. Public Health and Preventive Medicine 1999; 208-19.

15. World Health Organization. Global TB control. WHO report 1998. Geneva. WHO/TB/98:237. 